\title{
Em busca de um novo paradigma para o seguro rural no Brasil
}

Vitor A. Ozaki

Resumo: A implementação de um programa de seguro rural é uma reivindicação antiga do setor agropecuário no país. Após a malsucedida experiência da Companhia Nacional de Seguro Agrícola o governo voltou a tomar medidas para incentivar o mercado, por intermédio da Lei $\mathrm{n}^{\circ} 10.823 / 03$, que subvenciona parte do prêmio pago pelo produtor. A natureza deste trabalho é essencialmente analítica, de tal forma que não foram estabelecidos modelos quantitativos. Historicamente, os resultados deficitários do Proagro e de diversas seguradoras demonstram que o atual modelo de seguro agrícola apresenta fortes sinais de esgotamento. $\mathrm{O}$ artigo mostra as principais iniciativas, tanto privadas como governamentais e sugere um conjunto de medidas visando o desenvolvimento do seguro rural no país.

Palavras-chave: seguro rural, paradigma, subvenção

\section{Classificação JEL: Q19}

Abstract: The implementation of a crop insurance program is an old requirement of the agricultural sector. After the failure of the National Crop Insurance Company (CNSA), in the period of 1954 through 1966, the federal government started to stimulate the agricultural insurance

Professor Doutor do Departamento de Ciências Exatas - Matemática e Estatística. Escola Superior de Agricultura Luiz de Queiroz - USP. Email: vitorozaki@yahoo.com.br 
market. Aiming increase the crop insurance operations the Government approved Law n. 10.823 which subsidize part of the premium paid by farmers. The nature of this work is essentially analytical, such that any quantitative model has been established. Over the years, government risk management tools, such as, Proagro and some private insurance companies have had unsatisfactory financial results suggesting that the current crop insurance model presents signals of decline. This article shows the main initiatives, state and private, and suggests a set of measures to develop the agricultural insurance in the country.

Keywords: crop insurance, paradigm, subsidy

JEL Classification: Q19

\section{Introdução}

Ao longo dos anos, os produtores criaram diversos mecanismos para administração e mitigação do risco, tais como: a diversificação de culturas, diversificação espacial e sociedades mútuas. Apesar de serem relativamente eficientes no controle do risco, tais mecanismos comprometem o retorno esperado do empreendimento, devido ao trade off existente entre risco e retorno, ou seja, maiores retornos esperados estão associados a maiores níveis de risco.

Alguns produtores podem escolher maximizar seu retorno dado certo nível aceitável de risco. Por sua vez, outros decidem minimizar seu risco associado ao retorno desejado. Percebe-se que a estratégia de gestão de risco é um tanto quanto subjetiva e pode variar consideravelmente entre produtores de uma determinada região.

Por exemplo, se um produtor de soja utilizar corretamente seus insumos e contar com o clima favorável obterá, possivelmente, um retorno elevado no final da safra. Entretanto, intempéries climáticas podem reduzir consideravelmente sua produção e causar graves prejuízos econômicos. Caso o indivíduo seja averso ao risco, substituirá parte da área em produção de soja por outra cultura que exija menor necessidade de aplicação de insumos. Desta forma, o produtor reduz o risco, mas ao mesmo tempo diminui o lucro esperado da atividade. 
Quase todas as estratégias de mitigação do risco estão relacionadas a um maior ou menor trade off. Entretanto, existe um mecanismo que permite reduzir o risco sem grandes oscilações no retorno esperado: o seguro.

O seguro é notadamente um dos mecanismos mais eficazes para transferir o risco para outros agentes econômicos. Por meio dele um indivíduo transfere uma despesa futura e incerta (dano), de valor elevado, por uma despesa antecipada e certa de valor relativamente menor (prêmio) (Ozaki, 2005).

Neste contexto, o seguro da atividade agrícola pode ser visto como um importante instrumento para a estabilização financeira dos produtores. Entretanto, diversos entraves inibem a alavancagem das operações nesse mercado. São eles: problemas relacionados à assimetria de informação - o risco moral e a seleção adversa (Arrow, 1968; Arrow, 1991; Chambers, 1989; Goodwin e Smith, 1998; Pauly, 1968; Pauly, 1974; Akerlof, 1970; Quiggin, Karagiannis e Stanton, 1994), o risco catastrófico (Miranda e Glauber, 1997) e a ausência de metodologias adequadas de precificação, bem como a falta de séries históricas de dados estatísticos relativamente longas que possam refletir, precisamente, a estrutura de risco dos produtores (Ozaki, 2005).

$\mathrm{O}$ artigo analisa a busca de um novo paradigma para o seguro rural no país visando o equilíbrio econômico do mercado. Para isso, na seção 2 retoma-se o modelo econômico do seguro para verificar - sob certas pressuposições - porque um produtor averso ao risco prefere adquirir um contrato de seguro ao invés de reter o risco. A seção 3 mostra a evolução do seguro rural. Na seção 4, aborda-se de forma analítica as principais iniciativas do governo federal e dos governos estaduais e o posicionamento estratégico das seguradoras no mercado. Na seção 5, discute-se o papel das sociedades mútuas na administração do risco agrícola e na seção 6 conclui-se o artigo.

\section{A Economia do Seguro e seus Benefícios}

Um dos principais benefícios da utilização do seguro é que este mecanismo permite ao indivíduo igualar sua renda quando ocorre um evento danoso à situação em que tal evento não ocorre, mediante o 
pagamento de um prêmio e o recebimento de uma compensação, caso ocorra o sinistro (Rothschild e Stiglitz, 1976; Arrow, 1971).

Desta forma, considere um indivíduo que tenha inicialmente uma dotação contingente representada pela sua renda $\mathrm{W}$ e condicionada à ocorrência de um evento natural. Assim, na ocorrência de um acidente sua renda será $\mathrm{W}_{2}=\mathrm{W}_{1}-d$, na qual $d$ é o prejuízo causado pelo acidente e $\mathrm{W}_{1}$, caso contrário.

Suponha que existam apenas dois estados da natureza e uma commodity transacionada. No estado 1 não ocorre acidente com probabilidade $(1-\varpi)$ e sua renda inicial será $\mathrm{W}_{1}^{0}$. No estado 2 ocorre acidente com probabilidade $\varpi$ e $\mathrm{W}_{2}^{0}$ será sua renda neste estado. $\mathrm{O}$ valor esperado da renda deste indivíduo na situação inicial será:

$$
\overline{\mathrm{W}}^{0}=(1-\varpi) \mathrm{W}_{1}^{0}+\varpi \mathrm{W}_{2}^{0}=\mathrm{W}_{1}^{0}-\varpi d
$$

A utilidade esperada será representada por:

$$
\mathrm{U}(\mathrm{W})=(1-\varpi) \mathrm{U}\left(\mathrm{W}_{1}^{0}\right)+\varpi \mathrm{U}\left(\mathrm{W}_{2}^{0}\right)
$$

Em que $\mathrm{U}(\cdot)$ é função de utilidade esperada de von Neumann-Morgenstern (vN-M) ou função de utilidade de Bernoulli ${ }^{1}$.

Através da aquisição de um contrato de seguro, o indivíduo poderá atingir outra distribuição de renda diferente da inicial. Neste caso, suponha que uma firma seguradora ofereça um contrato de seguro, $q$, totalmente especificado pelo prêmio $P$ e pela indenização $I$, de modo que $q=(P, I)$. O Quadro 1 mostra as afirmações até agora realizadas.

Quadro 1. Situação do indivíduo com e sem seguro nos estados 1 e 2.

\begin{tabular}{ccc}
\hline Situação & Renda & Estado \\
\hline Sem seguro & $\mathrm{W}_{1}^{0}$ & 1 \\
& $\mathrm{~W}_{1}^{0}-d=\mathrm{W}_{2}^{0}$ & 2 \\
Com seguro & $\mathrm{W}_{1}^{0}-P$ & 1 \\
& $\mathrm{~W}_{1}^{0}-P-d+I$ & 2 \\
\hline
\end{tabular}

${ }^{1}$ A função de utilidade esperada foi inicialmente investigada por Bernoulli (1954), através de um famoso e interessante paradoxo, o paradoxo de Saint Petersburg, que ilustra a dificuldade na época de dissociar o valor do dinheiro de sua utilidade. 
Com a aquisição de seguro, o valor esperado da sua renda será:

$$
\overline{\mathrm{W}}_{\mathrm{q}}=(1-\varpi)\left(\mathrm{W}_{1}^{0}-P\right)+\varpi\left(\mathrm{W}_{2}^{0}-P+I\right)=\mathrm{W}_{1}^{0}+\varpi(d-I)-P
$$

A utilidade esperada será:

$$
\mathrm{U}_{q}(\mathrm{~W})=(1-\varpi) \mathrm{U}\left(\mathrm{W}_{1}^{0}-P\right)+\varpi \mathrm{U}\left(\mathrm{W}_{2}^{0}-P+I\right)
$$

O critério de decisão utilizado pelo indivíduo para adquirir o contrato será aquele, no qual a utilidade esperada na situação com seguro será maior ou igual à utilidade esperada na situação sem seguro $\mathrm{U}_{q} \geq \mathrm{U}$.

Sendo o lucro esperado da firma igual a $(1-\varpi) P-\varpi(I-P)$, definindo a indenização líquida como $I_{\mathrm{L}}$, tal que $I_{\mathrm{L}}=I-P$, e assumindo que o lucro da firma seguradora é zero, dada a pressuposição de competição perfeita, então $(1-\varpi) P-\varpi(I-P)=0$. Denotando o prêmio como um percentual, $\phi$, tal que $\phi \in[0,1]$, da importância segurada ou valor máximo da indenização, de modo que $P=\phi I$, então, rearranjando os termos, tem-se que $\varpi /(1-\varpi)=P / I_{\mathrm{L}}=\phi /(1-\phi)$, que implica que $\varpi=\phi$, ou do mesmo modo, $P=\varpi I$.

O prêmio é considerado atuarialmente justo, ou somente "prêmio justo" quando a probabilidade de um acidente ocorrer é igual ao prêmio por unidade de compensação ou quando o prêmio for igual à indenização esperada. O problema do indivíduo será então:

$\operatorname{Max}_{I}\left[(1-\varpi) \mathrm{U}\left(\mathrm{W}_{1}^{0}-P\right)+\varpi \mathrm{U}\left(\mathrm{W}_{1}^{0}-P-\mathrm{d}+I\right)\right]$

Sj. a $P-\phi I=0$

Das condições de primeira ordem resulta que:

$$
\frac{\mathrm{U}^{\prime}\left(\mathrm{W}_{1}^{0} \square \square I\right)}{\mathrm{U}^{\prime}\left(\mathrm{W}_{2}^{0} \square I \square \square I\right)} \square \frac{\pi}{(1 \square \pi)} \frac{(1 \square \square)}{\square}
$$

Quando o prêmio é justo, então $\mathrm{U}^{\prime}\left(\mathrm{W}_{1}^{0} \square \square I\right) \square \mathrm{U}^{\prime}\left(\mathrm{W}_{2}^{0} \square I \square \square I\right)$, se e somente se, $\mathrm{W}_{1}^{0}=\mathrm{W}_{2}^{0}+I$, ou $I=d$, ou seja, quando toda a perda é indenizada. Nesta situação, o seguro é dito ser um "seguro completo".

Definindo, deste modo, o contrato de seguro justo e completo como aquele em que $q=(\varpi d, d)$, ou seja, o prêmio justo é igual à perda esperada, mas como toda a perda é indenizada, $d=I$, então se diz que o prêmio justo é igual à indenização esperada. 
O ponto ótimo de compensação escolhido pelo indivíduo maximizador de sua utilidade será o ponto $\bar{W}\left(\mathrm{~W}_{1}^{0}-\varpi d, \mathrm{~W}_{2}^{0}+(1-\varpi) d\right)$ (Figura 1).

Figura 1. Ótimo individual

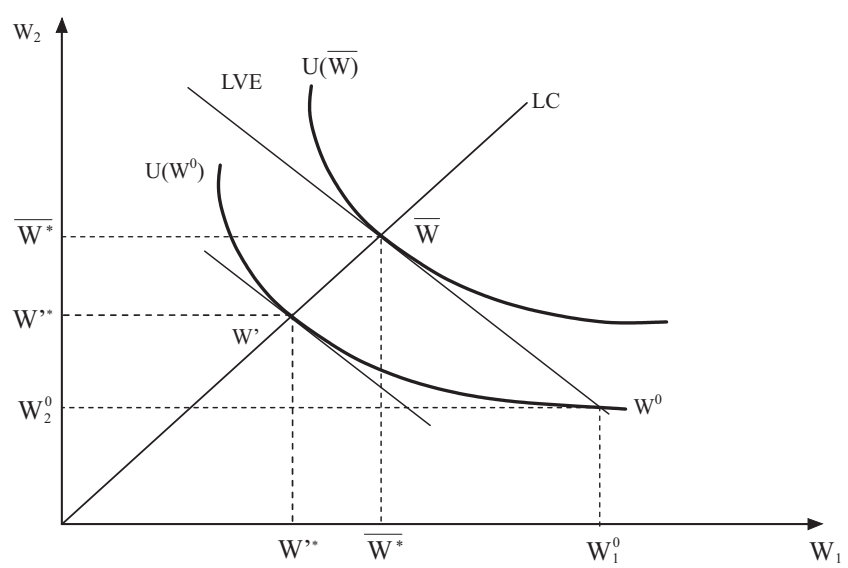

Nesta situação o valor esperado da renda será:

$\overline{\mathrm{W}}_{\mathrm{q}}^{\mathrm{c}}=(1-\varpi)\left(\mathrm{W}_{1}^{0}-P\right)+\varpi\left(\mathrm{W}_{2}^{0}+I-P\right)=\mathrm{W}_{1}^{0}-\varpi d$

A equação 7 mostra que o valor esperado da renda na situação com contrato de seguro completo e justo será igual ao valor esperado na situação inicial, ou seja, $\overline{\mathrm{W}}_{\mathrm{q}}^{\mathrm{c}}=\overline{\mathrm{W}}^{0}$. Além disso, sob a pressuposição de que o indivíduo tem aversão ao risco², pode-se perceber pela Fig. 1 que o contrato de seguro justo e completo é preferível à situação sem seguro, isto é, $\mathrm{U}(\overline{\mathrm{W}})>\mathrm{U}\left(\mathrm{W}^{0}\right)$. Nota-se também que, este contrato permite ao indivíduo trocar a distribuição da renda incerta $\left(\mathrm{W}_{1}^{0}, \mathrm{~W}_{2}^{0}\right)$ pela renda certa $\overline{\mathrm{W}}$.

Embora o mercado de seguros, sob a pressuposição de competição perfeita, seja teoricamente viável, na prática existem diversas falhas de mercado que impossibilitam seu pleno desenvolvimento. No setor agrícola essa situação se torna ainda mais complexa em virtude dos problemas supramencionados.

Como resultado, em diversos países em que o seguro agrícola é operacionalizado, como EUA, Japão, Canadá e Índia, a performance atuarial dos

$2 \frac{\partial \mathrm{U}}{\partial \mathrm{W}_{\mathrm{i}}}=\mathrm{U}^{\prime}\left(\mathrm{W}_{\mathrm{i}}\right)>0$ e $\frac{\square^{2} \mathrm{U}}{\square \mathrm{W}_{\mathrm{i}}^{2}} \square \mathrm{U}^{\prime \prime}\left(\mathrm{W}_{\mathrm{i}}\right) \square 0$, para i $=1,2$. 
programas de seguro agrícola tem sido pouco satisfatória. O total de prêmios arrecadados tem sido inferior ao montante de indenizações pagas ao longo dos anos. Ademais, existe forte participação governamental na forma de subsídios (Ray, 1985; Dandekar, 1985; Gardner e Kramer, 1986; Lopes e Dias, 1986; Yamauchi, 1986; Sigurdson e Sin, 1994; Wright e Hewitt, 1994; Goodwin e Smith, 1995; Mosley e Krishnamurthy, 1995; Miranda, et al. 1999). No Brasil, historicamente, as poucas experiências com o seguro agrícola não apresentaram resultados satisfatórios (Ozaki, 2006b).

\section{Síntese Histórica do Seguro Rural ${ }^{3}$ no Brasil}

Uma das primeiras experiências com o seguro agrícola no país ocorreu no Estado de São Paulo, no final da década de 1930, por meio do seguro contra granizo. O grande desenvolvimento desse seguro originou a Carteira de Seguro Contra o Granizo, sob a forma de fundos.

Em 1948 foi criada a Carteira Agrícola de Seguros Contra o Granizo para os viticultores do Estado de São Paulo. Os recursos foram constituídos pela arrecadação da taxa de seguro ( $8 \%$ sobre a indenização total pretendida pelo segurado). A carteira ficou sob a administração da Comissão de Produção Agropecuária (CPA) e vinculada a Secretaria da Agricultura do Estado de São Paulo. A Comissão passou a administrar também a Carteira de Seguros Contra o Granizo. Posteriormente, passou a ser denominada Carteira de Seguro Contra o Granizo para a Lavoura Algodoeira.

Neste período, o governo federal sancionou a Lei $n^{\circ} 2.168 / 54$, que regulamentou e estabeleceu as normas para o seguro rural no país. Entre outras atribuições, a referida Lei: i)Permitiu ao Instituto de Resseguros do Brasil (IRB) realizar os estudos pertinentes e o planejamento para a instituição do seguro rural, subscrever os riscos e estabelecer as taxas de prêmio dos seguros; ii) Estabeleceu a criação do Fundo de Estabilidade do Seguro Agrário, sob a administração do IRB, com o objetivo de garantir a estabilidade do mercado securitário (rural) e cobrir riscos de catástrofe; e, iii) Criou a Companhia Nacional de Seguro Agrícola (CNSA) com o intuito de desenvolver progressivamente operações de seguros rurais.

\footnotetext{
${ }^{3}$ De acordo com a SUSEP, por seguro rural entende-se o conjunto de todas as modalidades do ramo rural, tais como: agrícola, pecuário, benfeitorias e produtos agropecuários, penhor rural, florestas, vida, aqüícola e CPR. Esta seção foi baseada em Ozaki (2005).
} 
A CNSA operacionaliza o seguro em todo o país, por meio de suas filiais espalhadas em cinco regiões no Centro-Sul. Basicamente, operava dois tipos de seguros agrícolas: o de colheitas mínimas, aplicada ao algodão herbáceo, trigo e ao arroz, e o seguro de danos nas plantações, que cobria a cultura do café e videira. Esse último era baseado no valor convencional do pé. A indenização era calculada pelo número de pés existentes. A companhia também oferecia seguro pecuário, cobrindo riscos de rebanhos bovinos.

Em meados da década de 60, o governo do Estado de São Paulo criou a Carteira Agrícola de Seguros Contra a Geada para Horticultores, Floricultores e Fruticultores, na Secretaria da Agricultura, com a finalidade de amparar e defender horticultores, floricultores e fruticultores. Enquanto isso, a CNSA não conseguia equilibrar suas contas. Durante diversos anos os resultados foram deficitários. A companhia operou por trezes anos sendo dissolvida por meio do Decreto-Lei $n^{\circ} 73 / 66$.

Este documento alterou a Lei $\mathrm{n}^{\circ} 2.168 / 54$, na medida em que: i) Constituiu o Fundo de Estabilidade do Seguro Rural (FESR); ii) Determinou que o seguro do financiamento da atividade agropecuária realizada pelas instituições financeiras ligadas ao Sistema Nacional de Crédito Rural (SNCR) fosse obrigatório; iii) Estabeleceu que as operações de seguro rural ficariam isentas de qualquer tipo de tributação federal; iv) Permitiu que o governo federal assumisse riscos catastróficos, por intermédio do IRB; e, v) Obrigou que o seguro obedecesse às normas e limites fixados pelo Conselho Nacional de Seguro Privado (CNSP) e que o financiamento dos prêmios pelas instituições financeiras fosse obrigatório.

O Decreto-Lei $n^{\circ} 73 / 66$ impediu a Secretaria da Agricultura do Estado de São Paulo de continuar operando o seguro rural. Por isso houve a necessidade de se constituir uma seguradora própria do Estado. Assim, no mesmo ano, foi criado a Ipesp - Seguros Gerais S/A, que absorveu as carteiras de seguro agrícola da Secretaria da Agricultura e o Serviço Autônomo de Seguros Ipesp, Instituto de Previdência Social do Estado, que segurava o patrimônio de imóveis do governo estadual.

Dois anos depois, a Ipesp - Seguros Gerais S/A passou a denominarse Companhia de Seguros do Estado de São Paulo (Cosesp). O Decreto $\mathrm{n}^{\circ} 50.890 / 68$ obrigou todos os seguros contratados por órgãos do poder 
público estadual, sociedades anônimas, autarquias e entidades de economia mista fossem realizados por intermédio da Cosesp (Ozaki, 2006b).

A Resolução $n^{\circ}$ 5/70 do CNSP aprovou as normas tarifárias e condições gerais de seguro rural. Inicialmente, o seguro seria realizado em caráter experimental por meio da Cosesp, no Estado de São Paulo. Mais tarde, em 1972, foram estabelecidas as normas e condições para o Estado de Minas Gerais e, posteriormente, para os Estados do Rio de Janeiro e Rio Grande do Sul, por meio das Resoluções $n^{\circ} 15$, de 28 de junho de 1976 e $\mathrm{n}^{\circ} 10$, de 14 de maio de 1978, respectivamente.

Nesses Estados o seguro rural foi operacionalizado por seguradoras estatais. Em Minas Gerais, pela Companhia de Seguros de Minas Gerais (Cosemig), que passou a denominar-se Bemge - Companhia de Seguros de Minas Gerais, em 1974. No Rio de Janeiro, pelo Banco Estadual do Rio de Janeiro (Banerj), por meio de sua carteira rural. No Estado do Rio Grande do Sul foi implementado, em caráter experimental, pela Companhia União de Seguros Gerais.

Todas as seguradoras estatais descontinuaram suas atividades no ramo rural, em virtude dos sucessivos déficits e do processo de privatização ocorrido em meados da década de 90. Inclusive a Cosesp que operou no ramo rural por aproximadamente 30 anos encerrou suas operações na modalidade agrícola em 2005. Desde o início das operações até $\mathrm{o}$ ano safra 2001/02, o índice de sinistralidade ${ }^{4}$ foi maior do que um em 18 dos 27 anos (Tabela 1 e Figuras 2 e 3).

Tabela 1. Resultados do seguro agrícola do algodão, nos anos-safra de $1974 / 75$ a $1977 / 78$

\begin{tabular}{lccccc}
\hline \multicolumn{1}{c}{ Safra } & $\begin{array}{c}\mathrm{N}^{0} \text { Seguros } \\
\text { Realizados }\end{array}$ & $\begin{array}{c}\text { Área Segurada } \\
\text { (hectares) }\end{array}$ & $\begin{array}{c}\mathrm{N}^{\circ} \text { Sinistros } \\
\text { Pagos }\end{array}$ & $\begin{array}{c}\text { Área Sinistrada } \\
\text { (hectares)) }\end{array}$ & Sinistralidade \\
\hline $1974 / 75$ & 37.205 & 333.654 & 1.369 & 19.961 & 1,035 \\
$1975 / 76$ & 20.103 & 220.517 & 1.838 & 30.201 & 2,032 \\
$1976 / 77$ & 30.803 & 358.039 & 1.734 & 39.625 & 0,814 \\
$1977 / 78$ & 27.003 & 339.029 & 2.618 & 47.698 & 2,152 \\
Total & 115.117 & 1.251 .239 & 7.559 & 137.485 & 1,550 \\
\hline
\end{tabular}

Fonte: Gimenes (1979), extraído de Ozaki (2006a)

${ }^{4}$ Representa o total de indenizações pagas sobre o montante de prêmios arrecadados. 
Figura 2. Sinistralidade para a cultura algodoeira no período $1979 / 80$ a $1989 / 90$

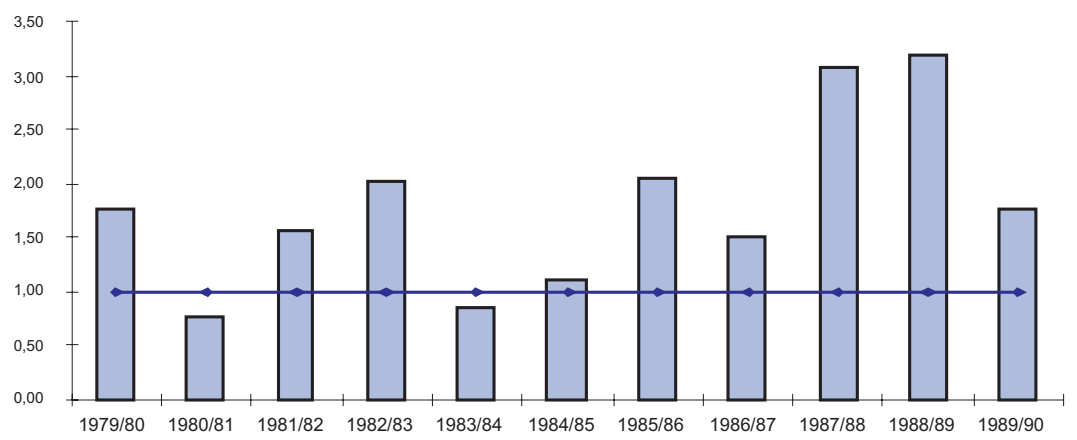

Fonte: Cosesp (2002), extraído de Ozaki (2006a)

Figura 3. Evolução do índice de sinistralidade da carteira agrícola da Cosesp no período 1991/92 a 2001/02

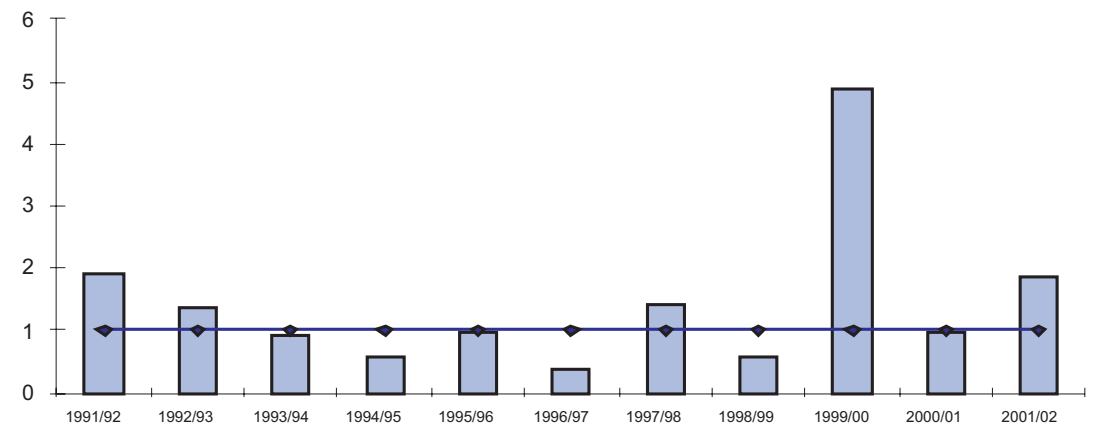

Fonte: Cosesp (2002), extraído de Ozaki (2006a)

Após a dissolução da CNSA, em 1966, o governo federal retomou suas iniciativas de proteção ao setor rural criando, em 1973, o Programa de Garantia da Atividade Agropecuária - Proagro ${ }^{5}$, regulamentado pela resolução $n^{0}$ 301/74 do Banco Central (Rossetti, 1998; Rossetti, 2001). O Programa não apresentou bons resultados desde o início. Nos cinco primeiros anos, a

${ }^{5}$ O Proagro garante a capacidade do sistema financeiro caso o produtor fique inadimplente junto ao agente financeiro em decorrência de um evento que causasse prejuízos à sua atividade. O programa foi criado para oferecer ao setor produtivo segurança quanto ao permanente fornecimento de crédito. Portanto, não garante a produção agrícola, deixando o produtor financeiramente descoberto em caso de sinistro. 
sinistralidade, que é o total pago em indenizações dividido pelo total arrecadado em prêmios, foi maior do que um em todos os anos. Particularmente, no primeiro ano, o prejuízo foi relativamente alto. A Tabela 2 e as Figuras 4 e 5 ilustram a performance do Proagro desde o seu início até 1998.

Tabela 2. Sinistralidade do Proagro, nos primeiros cinco anos de operacionalização

\begin{tabular}{cc}
\hline Ano & Sinistralidade \\
\hline 1975 & 84,8 \\
1976 & 8,2 \\
1977 & 10,1 \\
1978 & 9,3 \\
1979 & 16,5 \\
\hline
\end{tabular}

Fonte: Banco Central (2003)

Figura 4. Índice de sinistralidade do Proagro no período de 1980 a 1991 (Resultados até 14 de agosto)

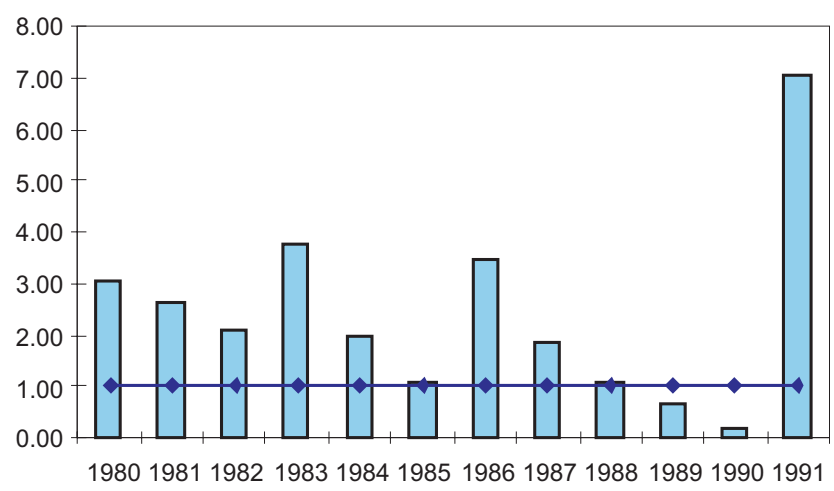

Fonte: Banco Central (2003)

É interessante apontar que o Proagro não é um mecanismo de seguro, na medida em que o seguro agrícola é regulamentado e fiscalizado pelos órgãos que tratam do seguro privado, enquanto o Proagro constitui um programa governamental de apoio à produção agrícola havendo a possibilidade de captação de recursos orçamentários sob a orientação da política agrícola do governo. 
Apesar disso, desde sua criação até meados de 2003, o Proagro foi (no âmbito do governo federal) a única forma de proteção ao financiamento disponível aos produtores contra eventuais perdas causadas por fenômenos climáticos adversos. O seguro agrícola teve importância secundária como forma de administração de risco promovida pelo governo federal.

Figura 5. Índice de sinistralidade do Proagro no período de 1991 a 1997.

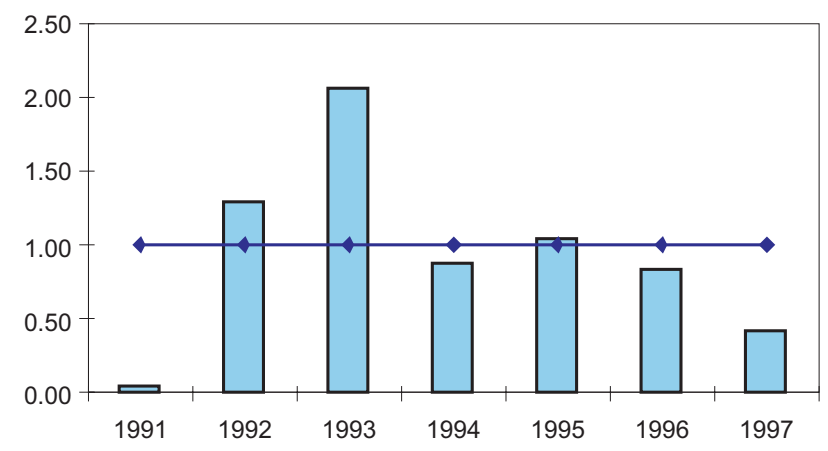

Fonte: Banco Central (2003)

Nota: os valores relativos a 1991 são após 14 de agosto

\section{Novos Rumos para o Mercado Segurador Rural}

Recentemente, este cenário mudou. O governo aprovou a Lei federal $n^{0} 10.823 / 03$, que concedeu subvenção em parte do prêmio pago pelo produtor $^{6}$, e também criou o Comitê Gestor Interministerial do Seguro Rural ligado ao Ministério da Agricultura, Pecuária e Abastecimento (MAPA) (Brasil, 2005c).

A regulamentação da Lei ocorreu alguns meses mais tarde por meio do Decreto n 5.121/04 (Brasil, 2005a). Finalmente, após quase 50 anos, o governo federal decidiu tomar medidas que pudessem impulsionar e criar o ambiente favorável para o desenvolvimento do seguro rural no Brasil. De modo geral, pode-se destacar três medidas importantes:

i) A subvenção econômica do prêmio do seguro rural, sob a denominação "Programa de Subvenção ao Prêmio do Seguro Rural (PSP)";

${ }^{6}$ Esta medida reduz consideravelmente o preço do seguro para o produtor, que paga apenas $(1-\mathrm{s})^{*} P$, onde $\mathrm{s}$ é o subsídio ao prêmio, em termos percentuais e $P$ o prêmio. 
ii) Criação do Comitê Gestor Interministerial do Seguro Rural (CGI), das Comissões Consultivas (CC) e uma Secretaria Executiva (SE);

iii) Estabelecimento do Plano Trienal do Seguro Rural (PTSR);

Os percentuais de subvenção para 2005 foram determinados através do Decreto $n^{\circ}$ 5.514, de 17 de agosto de 2005 (Brasil, 2005b). Além do percentual de subvenção, foram estabelecidos também o limite por produtor $^{7}$ (beneficiário, pessoa física ou jurídica) em $\mathrm{R} \$ 7.000$ para as culturas de algodão, arroz irrigado, feijão, milho, milho segunda safra, soja e trigo (por ano civil) e R $\$ 13.000$ para as culturas de maçã e uva.

A Tabela 3 relaciona a cultura beneficiada com seu respectivo percentual de subvenção e o limite por produtor.

Tabela 3. Percentual de subvenção, por tipo de cultura, na safra 2004/05.

\begin{tabular}{lc}
\hline \multicolumn{1}{c}{ Culturas } & Subvenção (\%) \\
\hline Algodão & 40 \\
Arroz Irrigado & 30 \\
Feijão & 50 \\
Milho & 40 \\
Milho (2o safra) & 40 \\
Soja & 30 \\
Trigo & 40 \\
\hline Maçã & 30 \\
Uva & \\
\hline
\end{tabular}

Fonte: Brasil (2005b)

Em 2006, o governo federal aprovou o Decreto ${ }^{8} \mathrm{n}^{0} 5.782$, de 23 de maio de 2006, que ampliou o número de culturas cobertas, bem como o percentual de subvenção e o limite por produtor (Brasil, 2006c). A Tabela 4 mostra os novos percentuais de subvenção.

O valor máximo de R \$32.000,00 de subvenção, por beneficiário, pessoa física ou jurídica, por ano civil, é limitado para cada um dos seguintes grupos de culturas e modalidades: i) aveia, canola, cevada, centeio, milho segunda safra, sorgo, trigo e triticale; ii) abacaxi, alface, algodão, alho, amendoim, arroz, batata, berinjela, beterraba, cana-de-açúcar,

${ }^{7}$ Pelo Decreto, o produtor rural poderia receber o benefício cumulativamente.

${ }^{8}$ Revoga o Decreto n ${ }^{\circ} 5.514$, de 17 de agosto de 2005. 
cebola, cenoura, couve-flor, feijão, girassol, milho, morango, pepino, pimentão, repolho, soja, tomate e vagem; iii) ameixa, café, caqui, figo, goiaba, kiwi, laranja, limão e demais cítricos, maçã, nectarina, pêra, pêssego e uva; iv) pecuário; v) florestas; e, vi) aqüícola. Nota-se, porém, que o produtor poderá receber subvenção em mais de uma cultura dentro do mesmo grupo, desde que o total do benefício não ultrapasse o limite estabelecido.

Tabela 4. Percentual de subvenção, por tipo de cultura, na safra 2005/06.

\begin{tabular}{lc}
\hline \multicolumn{1}{c}{ Culturas } & Subvenção (\%) \\
\hline Feijão, milho segunda safra e trigo & 60 \\
Algodão, arroz, aveia, canola, centeio, cevada, milho, soja, sorgo & 50 \\
e triticale & 40 \\
Maçã e uva & \\
Abacaxi, alface, alho, ameixa, amendoim, batata, berinjela, be- & \\
terraba, café, cana-de-açúcar, caqui, cebola, cenoura, couve-flor, & 30 \\
figo, girassol, goiaba, kiwi, laranja, limão e demais cítricos, mo- & \\
rango, nectarina, pepino, pêra, pêssego, pimentão, repolho, toma- & \\
te e vagem & 30 \\
Pecuário & 30 \\
Florestal & 30 \\
Aqüicola & \\
\hline
\end{tabular}

Fonte: (Brasil, 2006c)

Nota: na safra 2006/07 todos os percentuais permaneceram os mesmos, exceto para maçã e uva que passaram de 40 para $50 \%$.

O Comitê tem um papel fundamental no PSP, pois tem a competência de organizar e definir as suas diretrizes e prioridades, bem como fiscalizar e coordenar os recursos destinados ao programa. Cabe às Comissões auxiliar o Comitê sobre assuntos que lhe forem submetidos por intermédio de sua SE, especialmente na elaboração do PTSR, que deverá conter as diretrizes gerais do programa.

Além do PSP, o governo federal criou também o Programa SeguroSafra ${ }^{9}$. Apesar do nome, este instrumento não é um seguro, mas sim um programa assistencialista com o objetivo de garantir uma renda mínima aos agricultores familiares da região Nordeste, do semi-árido do Estado

${ }_{9}^{9}$ Criado pela Lei $n^{\circ} 10.420 / 02$, alterado pela Lei $n^{\circ} 10.700 / 03$ e regulamentado pelo Decreto $n^{\circ} 4.363 / 02$. 
de Minas Gerais (norte de Minas Gerais e Vale do Jequitinhonha), da região Norte do Espírito Santo e nos municípios sujeitos a estado de calamidade ou situação de emergência em razão do fenômeno da estiagem (Brasil, 2003).

Os governos estaduais também iniciarem programas de incentivo ao seguro agrícola. No Rio Grande do Sul, o governo implantou o Sistema Estadual de Seguro Agrícola e o Fundo Estadual de Seguro Agrícola (Fesag) ${ }^{10}$, em 1999. O programa é subsidiado e operacionalizado por meio do Banco de Estado do Rio Grande do Sul S.A. (Banrisul), seguradoras, prefeituras e entidades ligadas aos produtores rurais, sob coordenação da Secretaria de Agricultura e Abastecimento. O Conselho de Administração do Seguro estabelece as diretrizes do programa, tendo como principal objetivo proteger a renda dos produtores familiares, na ocorrência de excesso de chuvas, secas, geadas, nevascas, ventos e raios.

Basicamente, existem três tipos de seguro, que variam de acordo com o público-alvo e o montante de subsídio. São eles: o Seguro Agrícola Básico (SAB), com 90\% de subvenção; o Seguro Agrícola Solidário (SAS), com $50 \%$; e, Promoção do Seguro Agrícola. Basicamente, este é um programa que privilegia os pequenos produtores de milho que operam com o Programa Troca-Troca de Sementes e pequenos produtores de uva.

No Estado de São Paulo, o governo também iniciou um programa de incentivo à participação ao seguro rural, denominado "Projeto Estadual de Subvenção do Prêmio do Seguro Rural (PESP)”, que se iniciou na safra 2003/04. O projeto prevê a subvenção ao prêmio do seguro das operações das cadeias de produção do agronegócio familiar, com o objetivo de redução do risco e de contribuir para a estabilidade econômica e social do Estado (São Paulo, 2003b).

As subvenções correspondem a $50 \%$ do prêmio e são destinadas às operações enquadradas em programas e projetos de interesse da economia estadual, por meio das seguradoras autorizadas a operar pelo Conselho de Orientação do Fundo (COF) ${ }^{11}$. Os recursos são provenientes do

${ }^{10}$ Conta com recursos do Fundo Rotativo de Emergência, contribuição dos prêmios dos agricultores, recursos orçamentários, recursos do governo federal e de fontes internacionais.

${ }^{11}$ Entre outras atribuições, o COF determina o percentual de subvenção do valor do prêmio do seguro. 
Fundo de Expansão do Agronegócio Paulista - O Banco do Agronegócio Familiar - FEAP (São Paulo, 2003a).

O apoio governamental no sentido de incentivar a demanda de contratos de seguro agrícola pelos produtores, por meio da subvenção ao prêmio, resultou na recuperação do ânimo das seguradoras em operar no ramo rural. Desde 2005, o volume de recursos públicos alocados ao Programa de Subvenção ao Prêmio vem aumentando exponencialmente (Figura 6). Até o início da década de 90, apenas as seguradoras estatais operavam no ramo rural. A partir de 1998, novas seguradoras privadas estenderam suas coberturas para o ramo rural.

Figura 6. Evolução dos recursos públicos alocados ao Programa de Subvenção ao Prêmio, no período 2005 a 2008, em milhões de R\$.

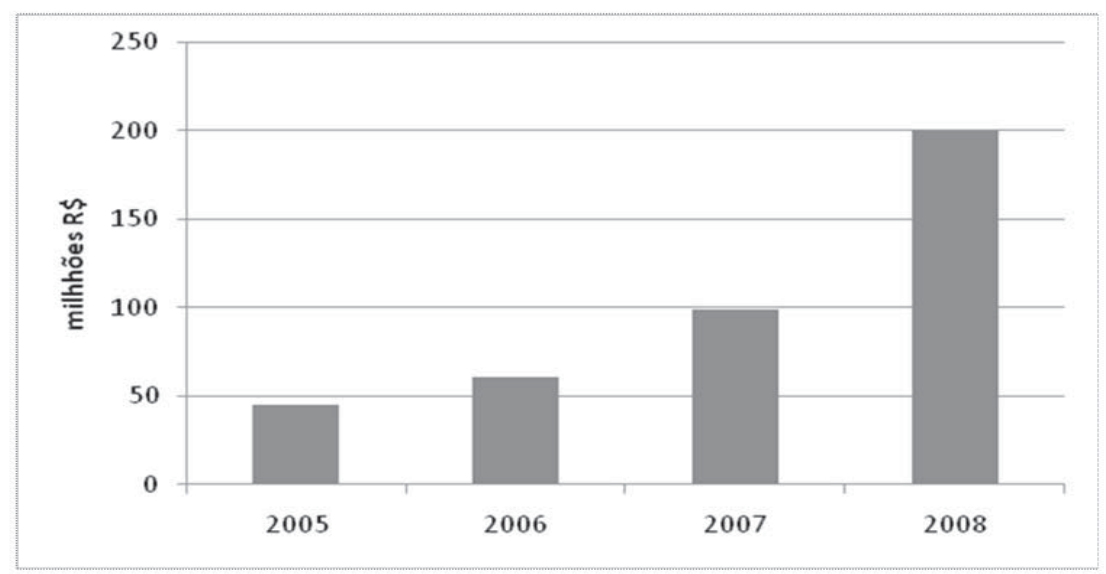

Fonte: Ministério da Agricultura, Pecuária e Abastecimento (2007)

Na safra 2005/06, seis seguradoras operam no mercado. São elas: ACE Seguradora S.A., AGF Brasil Seguros S.A., Cia de Seguros MinasBrasil, Companhia de Seguros Aliança do Brasil, Mapfre Seguradora S.A. e Seguradora Brasileira Rural S.A. A figura 7 mostra a participação de cada seguradora no mercado, em relação aos prêmios arrecadados.

Das seis seguradoras relacionadas, três atuam apenas no Estado de São Paulo: a SBR, a Ace e a AGF. As demais diversificam sua carteira em outros estados. Por exemplo, a seguradora Minas-Brasil concentrou suas operações nos Estados do Mato Grosso do Sul e Rio Grande do Sul. 
A Aliança do Brasil, nos Estados do Paraná e São Paulo, e a Mapfre, no Rio Grande do Sul. Na safra 2006/07, a seguradora Ace e a Minas Brasil saíram do mercado, permanecendo a Aliança do Brasil, AGF, Mapfre, SBR, e houve a entrada da Nobre seguradora. Na safra 2007/08, a seguradora Porto Seguro reiniciou suas operações com o seguro rural, após ter decidido não atuar na modalidade no final da década de 1990 .

Figura 7. Participação nos prêmios, por seguradora, modalidade agrícola, safra 2005/06.

Fonte: Susep (2006)

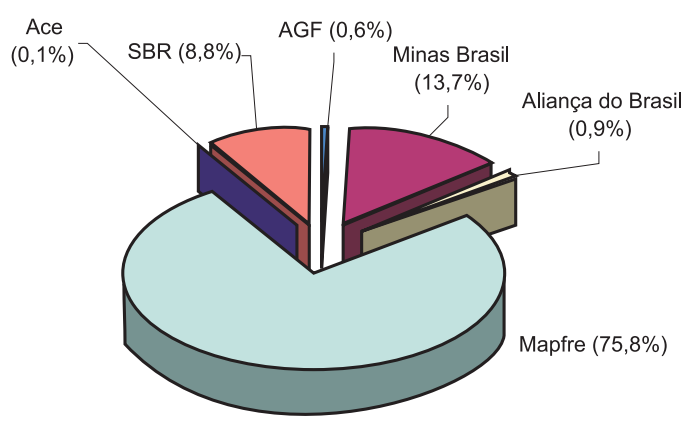

\section{O Papel do Seguro Mútuo na Mitigação do Risco}

Em muitas regiões em que não eram oferecidos seguros, os produtores ficavam completamente desprotegidos contra a ocorrência de fenômenos adversos. Nesse contexto, os produtores resolveram criar sociedades mútuas, por meio de suas cooperativas e associações.

Basicamente, no seguro mútuo, em lugar do prêmio, os segurados (mutualistas) contribuem com cotas necessárias para cobrir as despesas de administração e os prejuízos verificados. A responsabilidade pelo risco é compartilhada por todos os mutualistas. Isso cria o correto incentivo para a redução das fraudes, pois como os participantes rateiam os eventuais prejuízos, os segurados se fiscalizam uns aos outros (Caffagni e Marques, 1999).

Um problema potencial é a falta de algum tipo de resseguro, reservas ou fundos, para cobrir as perdas decorrentes de eventos generalizados, por exemplo, a seca, Assim, o seguro mútuo cobre perdas decorrentes de eventos que não apresentem sinistros espacialmente correlacionados, tais 
como, o granizo. Outro entrave refere-se ao fato do seguro mútuo não ser passível de cobertura pelo Fundo de Estabilidade do Seguro Rural (FESR).

Atualmente no país, o mutualismo é operacionalizado pela Cooperativa Agropecuária Batavo, a Cooperativa Agrária Mista Entre Rios e a Associação dos Fumicultores do Brasil (Afubra). De modo geral, esse mecanismo tem apresentado resultados favoráveis (superávit) devido à cobertura limitada e específica dos riscos, e também ao eficiente controle do risco moral a baixos custos.

\section{Conclusão}

No momento atual, o mercado de seguros, o governo e os produtores vivem momentos de grandes expectativas. A idéia de implementar um programa de seguro agrícola abrangente no país é relativamente antiga. Apesar disso, o seguro não conseguiu se estabelecer como instrumento de proteção ao setor rural.

O único programa governamental de garantia do financiamento vigente, o Proagro, passou por graves problemas de atraso no pagamento das indenizações, fraudes e dificuldades em sustentar elevados déficits. Na década de 90, o programa sofreu profundas modificações de caráter operacional, restringindo sua cobertura aos produtores enquadrados no zoneamento agrícola do MAPA.

Em busca de um novo paradigma para a questão do seguro rural, o governo federal e os governos estaduais (SP e RS) iniciaram programas de subvenção ao prêmio pago pelo produtor, que per se, representam um grande avanço em relação às iniciativas anteriores. Ademais, houve a estruturação de órgãos responsáveis pelo andamento e desenvolvimento do programa, como o Comitê Gestor Interministerial do Seguro Rural e as Comissões Consultivas, além do estabelecimento do Plano Trienal do Seguro Rural.

O subsídio tende a alavancar a demanda das operações de seguro agrícola, pois reduz o custo do seguro para o produtor. No entanto, a oferta de seguros em algumas regiões em que o risco é relativamente alto ficará comprometida. Uma possível solução seria subvencionar parte dos custo administrativo e operacional das seguradoras para motiválas a ofertar o seguro em locais mais arriscados, como ocorre nos EUA. 
Recentemente, as seguradoras privadas iniciaram suas operações no ramo rural atraídas pelo grande volume de recursos gerados no agronegócio ${ }^{12}$. Entretanto, a falta de dados estatísticos pode minar qualquer iniciativa de longo-prazo, como ocorreu com a CNSA. Ademais, recomenda-se que nas fases iniciais do programa deve ocorrer o planejamento minucioso e a execução de projetos-piloto, a fim de que experiências possam ser acumuladas e o déficit, se ocorrer, será minimizado. Ao longo dos anos, com o acúmulo de conhecimento e dados estatísticos, o seguro agrícola poderá ser ampliado para outras regiões. Desde o começo é imprescindível o apoio e o know how das resseguradoras internacionais.

A nova regulamentação do Fundo de Estabilidade do Seguro Rural (FESR) e a abertura do mercado de resseguros poderão garantir a segurança necessária para as seguradoras. Por meio do FESR as companhias poderão recuperar as perdas provenientes de sinistros catastróficos e a entrada de novas resseguradoras contribuirá para a transferência de boa parte do risco retido em suas carteiras.

Novos produtos estão sendo comercializados pelas seguradoras. Diferentemente do que ocorria no passado, em que havia apenas o seguro de custeio, hoje, os produtores podem contar com a cobertura do seguro de produção (que assegura a produção agrícola do produtor), seguro da cédula de produto rural (CPR), o seguro de insumos agropecuários, além das modalidades tradicionais (penhor rural, benfeitorias, etc.).

Outra alternativa de gestão de risco comumente utilizada são as sociedades mútuas operadas pelas cooperativas e associações agrícolas. Devido à ausência da cobertura do seguro em algumas regiões, os produtores organizaram seguros mútuos como forma de proteção contra algum tipo de evento fora do seu controle que cause danos econômicos. Este tipo de mecanismo tem gerado resultados positivos, mas tem a desvantagem de cobrir áreas relativamente pequenas.

Por fim, percebe-se que o governo tem concentrado seus esforços no desenvolvimento de um mercado de seguro agrícola sustentável financeiramente a médio e longo prazo. O seguro poderá ser um dos principais instrumentos de política agrícola anti-cíclica de administração de

${ }_{12}$ Estima-se que o PIB do agronegócio atingiu aprimadamente R 459 bilhões (2003). Este valor corresponde a $33,8 \%$ do PIB, $42 \%$ das exportações e $37 \%$ dos empregos (Marques, 2005). 
risco no país. Para isso recomenda-se a adoção das seguintes medidas: i) entrada efetiva do governo, tanto do ponto de vista financeiro, como institucional, por meio da criação de uma agência governamental com a finalidade de desenvolver, normatizar e regulamentar todo o sistema; ii) criar um ambiente adequado para o maior envolvimento das (re) seguradoras no sistema, por intermédio da agência governamental; desenvolver metodologias adequadas de precificação dos contratos; iii) constituir um novo Fundo de Catástrofe com maior agilidade no repasse dos recursos; iv) rever e atualizar a legislação vigente; v) investir em capacitação e formação de fiscais e peritos para monitorar o programa; e, vi) investir em uma agressiva e massificada campanha de propaganda do seguro agrícola.

\section{Referências bibliográficas}

AKERLOF, G.A. The market for "lemons": quality uncertainty and the market mechanism. Quarterly Journal of Economics, v.84, n.3, p.488500, Aug. 1970.

ARROW, K.J. Essays in the theory of risk bearing. Chicago: NorthHolland Publishing Company, 1971. 248p.

ARROW, K.J. The economics of agency. In: PRATT, J.W.; ZECKHAUSER, R.J. Principals and agents: the structure of business. Boston: Harvard Business School Press, 1991. 278p.

ARROW, K.J. The economics of moral hazard: further comment. American Economic Review, v.58, n.3, p.537-538, June 1968.

BERNOULLI, D. Exposition of a new theory on the measurement of risk. Econometrica, v.22, p.23-36, Jan. 1954.

BRASIL. Leis, decretos, etc. Decreto n ${ }^{\circ}$ 5.121, de 29 de junho de 2004. http://www.senado.gov.br/ legisla.htm (20 jan. 2005a)

BRASIL. Leis, decretos, etc. Decreto n ${ }^{\circ}$ 5.514, de 17 de agosto de 2005. http://www.senado.gov.br/ legisla.htm (20 jan. 2005b)

BRASIL. Leis, decretos, etc. Decreto ${ }^{\circ}$ 5.782, de 23 de maio de 2006. http://www.senado.gov.br/ legisla.htm (12 fev. 2006a) 
BRASIL. Leis, decretos, etc. Lei $n^{\circ} 10.823$ de 19 de dezembro de 2003. http://www.senado.gov.br/legisla.htm (20 jan. 2005c)

CAFFAGNI, L.C.; MARQUES, P.V. Seguro agropecuário no Brasil: instituições e problemas. Preços Agrícolas, v.14, n.152, p.16-18, jun. 1999.

CHAMBERS, R.G. Insurability and moral hazard in agricultural insurance markets. American Journal of Agricultural Economics, v.71, n.3, p.604-616, Aug. 1989.

DANDEKAR, V.M. Crop insurance in India: a review, 1976-77 to 198485. Economic and Political Weekly, v.20, n.25-26, p.A46-A59, 1985.

FETAG. Fetag contabiliza R \$ 6,3 bilhões de prejuízos com estiagem. http:// www. fetagrs.com.br/site/home/index.php?idprincipal = 73 (Set 2005)

GARNER, B.L; KRAMER, R.A. Experience with crop insurance programs in the United States. In: HAZELL, P.; POMAREDA, C.; VALDÉS, A. Crop insurance for agricultural development. Baltimore: The Johns Hopkins University Press, 1986. 322p.

GIMENES, A.C.F. Painel 2: O seguro de custeio agrícola no estado de São Paulo. In: SEMINÁRIO SOBRE SEGURO RURAL E PROAGRO, 1., Campinas, 1979. Anais. Campinas: Secretaria de Agricultura do Estado de São Paulo, Coordenadoria de Assistência Técnica Integral (CATI)/ Companhia de Seguros do Estado de São Paulo, 1979. p.1-14.

GOODWIN, B.K.; SMITH, V.H. The economics of crop insurance and disaster aid. Washington: American Enterprise Institute, 1995. 153p.

LOPES, M.R.; DIAS, G.L.S. The brazilian experience with crop insurance programs. In: HAZELL, P.; POMAREDA, C.; VALDÉS, A. Crop insurance for agricultural development. Baltimore: The Johns Hopkins University Press, 1986. 322p.

MARQUES, E.S. O estado da arte da agricultura brasiLeira. http://www. agricultura .gov.br (Setembro de 2005)

Ministério da Agricultura, Pecuária e Abastecimento. Política agrícola/seguro rural/estatísticas. http://www.agricultura.gov.br/ (Setembro de 2007).

MIRANDA, M.J.; GLAUBER, J.W. Systemic risk, reinsurance, and the 
failure of crop insurance markets. American Journal of Agricultural Economics, v.79, n.1, p.206-215, Feb. 1997.

MIRANDA, M.; SKEES, J.; HAZELL, P. Innovations in agricultural and natural disaster insurance for developing countries. Ohio: The Ohio State University, Department of Agriculture, Environment and Development, 1999. (Working paper)

MOSLEY, P.; KRISHNAMURTHY, R. Can crop insurance work? The case of India. The Journal of Development Studies, v.31, p.428-450, 1995.

OZAKI, V.A. Aspectos contratuais e preformance atuarial do seguro de custeio agrícola. Revista Paranaense de Desenvolvimento, n.109, jul/ dez 2006a.

OZAKI, V.A. Métodos atuariais aplicados à determinação da taxa de prêmio de contratos de seguro agrícola: um estudo de caso. Piracicaba, 2005. 324p. Tese (Doutorado) - Escola Superior de Agricultura "Luiz de Queiroz", Universidade de São Paulo.

OZAKI, V.A. O seguro rural estadual e as novas iniciativas privadas. Agricultura em São Paulo, v.53, n.1, p.91-106, jan/jun. 2006b.

OZAKI, V.A.; SHIROTA, R. Um estudo da viabilidade de um programa de seguro agrícola baseado em um índice de produtividade regional em Castro (PR). Revista de Economia e Sociologia Rural, v.43, n.3, p.485-503, 2005.

OZAKI, V.A.; SHIROTA, R. A experiência do seguro agrícola nos EUA: evolução e performance. Revista Brasileira de Risco e Seguro, v.1, n.2, p.69-87, 2005.

PAULY, M.V. Overinsurance and public provision of insurance: the roles of moral hazard and adverse selection. Quarterly Journal of Economics, v.88, n.1, p.44-62, Feb. 1974.

PAULY, M.V. The economics of moral hazard: comment. American Economic Review, v.58, n.3, p.531-537, June 1968.

QUIGGIN, J.; KARAGIANNIS, G.; STANTON, J. Crop insurance and crop production: an empirical study of moral hazard and adverse selection. In: HUETH, D.L.; FURTAN, W.H. Economics of agricultural crop insurance: theory and evidence. Boston: Kluwer Academic Publishers, 1994. 380p. 
RAY, P.K. Economics of crop insurance. Calcuta: Central Publishing Concern, 1981. 333p.

ROSSETTI, L.A. Seguridade e zoneamento agrícola no Brasil: novos rumos. In: SIMPÓSIO INTERNACIONAL DE SECURIDADE E ZONEAMENTO AGRÍCOLA DO MERCOSUL, 1., Brasília, 1998. Anais. Brasília: Ministério da Agricultura e Abastecimento/CER/PROAGRO/GM, 1998. p.1-10.

ROSSETTI, L.A. Zoneamento agrícola em aplicações de crédito e securidade rural no Brasil: aspectos atuariais e de política agrícola. Revista Brasileira de Agrometeorologia, v.9, n.3, p.386-399, 2001.

ROTHSCHILD, M.; STIGLITZ, J. Equilibrium in competitive insurance markets: an essay on the economics of imperfect information. Quarterly Journal of Economics, v.90, n.4, p.629-649, Nov. 1976.

SÃO PAULO (Estado). Leis, decretos, etc. Decreto ${ }^{\circ} 47.804$, de 30 de abril de 2003. Diário Oficial (Estado de São Paulo), v.113, n.82, 2003a.

SÃO PAULO (Estado). Leis, decretos, etc. Lei $\mathrm{n}^{\circ} 11.244$, de 21 de outubro de 2002. http://www.legalmatic.com.br/area_tributaria/icms/ leis/2002/L11244.htm (set. 2003b)

SIGURDSON, D.; SIN, R. An aggregate analysis of canadian crop insurance policy. In: HUETH, D.L.; FURTAN, W.H. Economics of agricultural crop insurance: theory and evidence. Boston: Kluwer Academic Publishers, 1994. 380p.

SUSEP. Superintendência de Seguros Privados. SES - Sistema de Estatísticas da SUSEP. http://www.susep.gov.br (06 jul. 2006)

YAMAUCHI, T. Evolution of the crop insurance program in Japan. In: HAZELL, P.; POMAREDA, C.; VALDÉS, A. Crop insurance for agricultural development. Baltimore: The Johns Hopkins University Press, 1986. 322p.

WRIGHT, B.D.; HEWITT, J.A. All-risk crop insurance: lessons from theory and experience. In: HUETH, D.L.; FURTAN, W.H. Economics of agricultural crop insurance: theory and evidence. Boston: Kluwer Academic Publishers, 1994. 380p. 